\title{
Our Buddies, Ourselves: The Role of Sexual Homophily in Adolescent Friendship Networks
}

\author{
Sarah L. Trinh \\ University of Michigan \\ Carolyn T. Halpern \\ University of North Carolina at Chapel Hill
}

\author{
Jaemin Lee \\ Duke University \\ James Moody \\ Duke University and King Abdulaziz University
}

\begin{abstract}
The present study tests the assumption that peers wield sufficient influence to induce sexual homophily (i.e., similarities in sexual experiences). Because girls face greater stigma for their sexual experiences than do boys, sexual homophily may be greater in girls' friendship networks than in boys'. Stochastic actor-based models were used to analyze network data $(n=2,566$; ages 14-18) from two high schools in the National Longitudinal Study of Adolescent to Adult Health. Sexual homophily was present in friendship networks. Girls and boys were equally susceptible to their friends' influence, but the former exhibited a stronger preference for befriending same sexual debut status peers than the latter. The findings suggest that adolescents-particularly girls- "curate" their networks to minimize peer ostracism.
\end{abstract}

Media, news, and policy each reflect ubiquitous assumptions that adolescents are sexually permissive, often as a result of their friends' undue influence. Yet, adolescent sexual homophily-the principle that adolescents' sexual experiences are similar to their peers' - is rarely subjected to rigorous empirical investigation. This oversight is surprising given the rich, multidisciplinary literature that consistently draws theoretical and empirical connections between social relationships and health across the life span (Umberson, Crosnoe, \& Reczek, 2011). Links between peer relations and adolescent health behaviors have primarily emerged from studies on public behaviors (e.g., smoking; Brown, Dolcini, \& Leventhal, 1997). Sexual behaviors are

This work was supported by a postdoctoral fellowship provided by the National Institute of Child Health and Human Development (T32-HD07376) through the Center for Developmental Science, University of North Carolina at Chapel Hill, to Sarah L. Trinh. This work was also supported by grants from the National Institute for Health (1R01HD075712, R25HD07935201A1) to James Moody (PI) and Jaemin Lee. James Moody was also supported for broadly similar work related to social network methods, health, and/or adolescents from grants R01 DA01822505A1 (NIDA), DARPA's Social Sim program, and James S. McDonnell Foundation. Effort by Carolyn T. Halpern was supported by the National Institute of Child Health and Human Development grants R01HD057046) to Carolyn T. Halpern (PI) and 5-R24-HD050924 to the Carolina Population Center at the University of North Carolina at Chapel Hill.

Correspondence concerning this article should be addressed to Sarah L. Trinh, Department of Psychology, University of Michigan, 530 Church St., Ann Arbor, MI 48109. Electronic mail may be sent to sltrinh@umich.edu. typically private, and the extent to which private behaviors are susceptible to peer influences is unclear. The notion that private behaviors are subject to public influences is a fundamental assumption underlying countless media campaigns and programs dedicated to safeguarding adolescent sexual health. Recent evidence suggests that these endeavors would be more effective if they were tailored to meet the specific needs of subgroups (Bearinger, Sieving, Ferguson, \& Sharma, 2007). For example, girls' endorsement of conventional gender expectations - that is, prioritizing others over themselves-is associated with sexual risk taking (Impett, Schooler, \& Tolman, 2006). If subgroups can be identified, then health practitioners and educators could meet adolescents' needs with greater precision (Bearinger et al., 2007). Therefore, finding sexual homophily in adolescent friendship networks yields meaningful insights for health promotion.

The present study had two objectives. The first objective was to investigate the presence and development of sexual homophily in middle to late adolescence (ages 14-18). We compared the sexual debut - that is, first sexual intercourse-statuses of adolescents and their friends to detect the presence of sexual homophily in friendship networks. We examined the contributions of selection and

(C) 2018 Society for Research in Child Development All rights reserved. 0009-3920/2019/9001-0035 DOI: $10.1111 /$ cdev.13052 
socialization toward the development of homophily. Selection is the process whereby individuals choose to associate with others who are already similar to them, and socialization is the process of individuals becoming similar to each other due to mutual influence (McPherson, Smith-Lovin, \& Cook, 2001). The second objective was to test for the differentiation of sexual homophily by gender by analyzing whether selection and socialization varied for girls and boys.

To meet these objectives, we used stochastic actor-based (SAB) models (Snijders, van de Bunt, \& Steglich, 2010), which permit simultaneous examination of selection and socialization while accounting for endogenous processes that contribute to homophily (e.g., homophily based on demographic characteristics). These models use longitudinal social network data and, as a result, address limitations that were common in previous research on sexual homophily: cross-sectional data, limited network data, and rare use of friends' self-reported data (e.g., Jaccard, Blanton, \& Dodge, 2005). Previous research has typically addressed the contributions of relational contexts at the individual level by surveying adolescents on their perceptions of and communications with their peers (e.g., Kapadia et al., 2012; Prinstein, Meade, \& Cohen, 2003; van de Bongardt et al., 2017). In the present study, analyses are situated squarely on adolescent peer networks, and this rigorous design presents an opportunity to replicate previous research with greater credibility.

Our contributions are not limited to the methods that we use; meeting our objectives yields insights for our understanding of gender and peer processes regarding private behaviors. Identifying who influences whom substantiates what we assume yet rarely demonstrate. That is, girls' and boys' capacities to influence their peers likely differ. Genderarguably the most essentialized social categoryimbues health and social relations (Mehta \& Strough, 2009). This simple fact has generated an expansive literature on gender differences. We extend this literature by considering how youthwho are inundated with messages about gender and sexuality (Kim et al., 2007) - respond to their peers' sexual debut statuses. Investigating peer relations regarding a private behavior also extends the literature on homophily in adolescent friendship networks, which typically focuses on public behaviors (e.g., Cheadle, Stevens, Williams, \& Goosby, 2013). Finally, our study is not only a rigorous replication of previous research on sexual homophily-both its presence and development-it is also an investigation of the differentiation of sexual homophily by gender.

\section{Peer Networks: Critical Sites for Sexual Socialization}

A small but rich literature on adolescent social networks in the United States yields similar findings of sexual homophily across contexts and diverse samples. Sexual homophily has been documented in junior high school (e.g., Billy, Rogers, \& Udry, 1984), high school (Suleiman \& Deardorff, 2015), and college samples (e.g., Holman \& Sillars, 2012), and in studies across the United States, including the Northeast (Prinstein et al., 2003) and the South (Wallace, Miller, \& Forehand, 2008). Sexual homophily has also been found in schools with predominantly White student populations (Prinstein et al., 2003) and diverse student populations (Billy \& Udry, 1985; Billy et al., 1984; Henry et al., 2007) as well as community- and clinic-based samples of Black (e.g., Dolcini, Catania, Harper, Boyer, \& Richards, 2012) and Latino youth (Kapadia et al., 2012). The prevalence of sexual homophily may reflect the salience of peer influence and selection during adolescence.

Adolescents are uniquely situated as sexual socialization agents because they serve in numerous roles: sex educators, relationship advisers, and matchmakers (Suleiman \& Deardorff, 2015). Adolescents' sensitivity to their peers' opinions facilitates this intimate exchange of support. Not surprisingly, adolescents' sexual attitudes and behaviors are frequently aligned with what their peers think and do, regardless of whether peers express their explicit approval or their approval is presumed (Dolcini et al., 2012; Kapadia et al., 2012; Prinstein et al., 2003). Meta-analyses demonstrate that adolescents report more sexual partners, earlier sexual debut, and more frequent sex if they believe their friends are sexually active, approve of being sexually active, and/or pressure them to become sexually active (van de Bongardt, Reitz, Sandfort, \& Deković, 2015). Because sexuality is so salient and so controversial, adolescents may feel particularly uneasy when their sexual experiences differ from their friends'.

Previous research has documented the presence of sexual homophily in adolescents' friendship networks, yet the development of homophily and the differentiation of homophily by gender remain understudied. The former issue is a reflection of a well-noted challenge and a source of tension in the literature on peer relations (Dishion, 2013). That is, homophily emerges from selection and socialization 
(Kandel, 1978; McPherson et al., 2001). An adolescent's sexual debut may be influenced by his or her friend's recent sexual debut, and this friendship may also be a consequence of shared sexual attitudes and beliefs (Suleiman \& Deardorff, 2015). Another possibility is the differentiation of sexual homophily by gender; sexual homophily may differ between girls' and boys' friendship networks. A common assumption is that sexual homophily is greater among same-sex friends than other-sex friends, as evidenced by previous research's dominant focus on adolescents and their same-sex best friends (e.g., Jaccard et al., 2005; Lefkowitz, Boone, \& Shearer, 2004). A model that comprehensively examines girls' and boys' friendship networks is necessary to examine these assumptions.

Our central argument is that sexual homophily likely differs between girls' and boys' friendship networks. Support for our argument is derived from theoretical and empirical work on the sexual double standard (Bordini \& Sperb, 2012). According to the sexual double standard, boys who unabashedly pursue and enjoy sex are "just being boys," but girls who do the same are often believed to be troubled and immoral (Bamberg, 2004). Indeed, "good girls" show sexual restraint (Phillips, 2000; Tolman, 2002). Adolescents understand the sexual double standard and adeptly use it to evaluate others and anticipate others' evaluations of themselves (e.g., Daniels \& Zurbriggen, 2016; Tolman, 2002). Girls report that female peers who are deemed promiscuous are ostracized (Tolman, 2002). Boys report that male peers who have many sexual partners are praised (Smiler \& Heasley, 2016). Sociometric data support these perceptions: Reporting more sexual partners is linked to receiving more friendship nominations for boys and receiving fewer friendship nominations for girls (Kreager \& Staff, 2009). The inverse association between sexual experience and peer acceptance among girls likely exists because adolescents stigmatize girls they see as lacking sufficient sexual restraint. Not surprisingly, girls may feel safer and more supported with similarly experienced friends (Lyons, Giordano, Manning, \& Longmore, 2011). Accordingly, we hypothesized that sexual homophily would be higher in girls' friendship networks than in boys'.

Adolescents-who are attuned to difference (Steinberg \& Monahan, 2007) — may find it difficult to reconcile differences between their own sexual attitudes and experiences and those of their peers'. Indeed, the moral, religious, and gendered underpinnings of sexuality may magnify such differences (Hull, Hennessy, Bleakley, Fishbein, \& Jordan, 2011).
Yet, gaining peer acceptance is a priority and a challenge for adolescents due to developmental reasons. Susceptibility to peer influence is highest in adolescence (Steinberg \& Monahan, 2007). By scrutinizing and policing their peers, adolescents ensure that adherents and violators are praised and punished, respectively, which has implications for their socioemotional and behavioral development (Rose \& Rudolph, 2006). For instance, adolescents may comply with said expectations to avoid backlash effects-social sanctions for counter-stereotypical behaviors (Conley, Ziegler, \& Moors, 2013). For girls, backlash effects may be especially harmful, as their friendships tend to be more fragile than boys' (Benenson \& Christakos, 2003). As balance theory suggests, adolescents may be motivated to reduce peer ostracism by maintaining their affiliations with likeminded others and by dissociating from dissimilar others (Davis, 1963). Not surprisingly, conversations among friends typically reflect and reinforce shared sexual attitudes and similar sexual experiences (Lefkowitz et al., 2004). For adolescents - especially adolescent girls - being similar to one's peers may provide them much-needed validation and support.

Sexual debut is a salient marker of difference for adolescents. The significance of sexual debut partly stems from the fact that its precursor-virginity-is laden with symbolic meanings. Moreover, the endorsement and interpretation of these meanings frequently vary by gender. For example, girls typically see virginity as a valuable "gift" that is ideally "given" with serious thought (Carpenter, 2002). In contrast, boys typically report feeling "burdened" by their virginity and proud of their sexual debut (Cohan, 2009; Kimmel, 2009). Peers appear to reinforce the meanings that adolescents tie to sexual debut. Boys are usually congratulatory to their male peers regarding their sexual debut and sexual experiences, unless the veracity of such experiences comes into question (Vanden Abeele, Campbell, Eggermont, \& Roe, 2014). Girls, however, are more discreet about their experiences and tend to express ambivalence regarding their own and their female peers' experiences (Harper, Gannon, Watson, Catania, \& Dolcini, 2004). Thus, the sexual double standard colors adolescents' responses to their own sexual debut and to their peers'.

Investigating sexual homophily is challenging due to the fact that friendships develop for any number of reasons, including demographic homophily (e.g., race, gender), shared interests (e.g., clubs), and propinquity (e.g., team sports). Friendships also develop from having mutual friends (i.e., transitivity), being highly visible while having high 
status (i.e., popularity), and from liking peers who already consider the individual their friend (i.e., reciprocity; Dijkstra, Cillessen, \& Borch, 2013; Dishion, 2013). Adolescents also appear to be sensitive to differences in pubertal development; early-maturing adolescent girls tend to befriend older peers (Cavanagh, 2004). Pubertal development also has implications for sexual homophily. Physical maturation suggests sexual maturation, and as a result, adolescents who appear adult-like have more opportunities to enter sexual relationships than their younger-looking peers; this is especially true for girls (Baams, Dubas, Overbeek, \& van Aken, 2015). The present study captures the multitude of social and developmental processes underlying friendship formation by utilizing $\mathrm{SAB}$ models for network dynamics. This approach permits simultaneous examination of selection and socialization while taking into account endogenous processes based on demographic characteristics and shared interests.

\section{Hypotheses}

Drawing from the multidisciplinary literature on peer relations and gendered sexual socialization, we developed two hypotheses. First, we hypothesized that an adolescent's sexual debut would be similar to his or her friends because homophily is frequently found across numerous characteristics - for example, delinquency and drug use (Osgood et al., 2013) - and because adolescents' discussions about sex typically reflect shared values (Lefkowitz et al., 2004). To test this hypothesis, we examined the contributions of both selection and socialization to sexual homophily. Our second hypothesis was derived from previous research documenting adolescents' use of the sexual double standard (e.g., Bamberg, 2004; Eder, Evans, \& Parker, 1995). That is, we hypothesized that sexual homophily would be greater among girls than among boys because girls are subjected to greater scrutiny and sanctions for their sexual attitudes and experiences than boys.

\section{Method \\ Description of Analysis Sample}

We analyzed data from the National Longitudinal Study of Adolescent to Adult Health (Add Health; Harris et al., 2009). Add Health is a schoolbased longitudinal survey of adolescents enrolled in grades 7 through 12 across 140 schools in the United States, beginning in the 1994-1995 school year. Respondents repeatedly made friendship nominations across three waves: Wave 1 in-school surveys (September 1994-April 1995), Wave 1 inhome interviews (April-December 1995), and Wave 2 in-home interviews (April-August 1996). For clarity, we refer to Wave 1 in-school survey as Time 1 , Wave 1 in-home interview as Time 2, and Wave 2 in-home interview as Time 3. Our analysis sample $(n=2,566)$ consisted of respondents in two large "saturated schools" - schools where network data were collected from nearly all adolescents. Studies on these two schools- "Jefferson High School" and "Sunshine High School" - are common due to their large size and complete network coverage (e.g., Haas \& Schaefer, 2014).

Respondents were asked to nominate up to five female friends and five male friends at each time point. The measure of each respondent's friendship network consisted of all of their friendship nominations, regardless of whether or not they were reciprocated. Nominations of friends outside their school were excluded because individual self-reported data were unavailable for those friends. To distinguish friends from romantic partners, all peers who were identified as friends and romantic partners were excluded.

\section{Measures}

\section{Sexual Debut}

Information for sexual debut was drawn from responses as to whether or not respondents have had sexual intercourse (yes $=1$, no $=0$ ). This question was asked in Times 2 and 3, but not in Time 1 . For Time 1, we constructed the dichotomous indicator for sexual debut by utilizing responses from an in-home interview question on the timing of one's sexual debut ("In what month and year did you have sexual intercourse for the very first time?"). Sexual debut status was coded as 1 at Time 1 if the date for first sexual intercourse fell before or during the Wave 1 in-school survey period. In turn, we were able to present our dependent variable across all time points. Our sample includes all respondents who filled out at least one survey questionnaire from Time 2 or 3.

\section{Endogenous Network Processes}

To better determine if adolescents become friends with one another due to shared sexual debut status, we controlled for endogenous processes underlying friendship formation: reciprocity, popularity, and transitivity. Individuals tend to reciprocate 
friendship ties (reciprocity), nominate highly visible peers as friends (popularity), and befriend friends of friends (transitivity).

\section{Sociodemographic Characteristics}

Because close friends tend to be similar to one another on demographic characteristics, we also included gender, race, religiosity, parental education, and age (McPherson et al., 2001; Mehta \& Strough, 2009). Dummy coding was used for gender $($ male $=1)$ and racial groups (White $=1$, nonWhite $=0$ ). Frequent attendance of religious services - a common proxy for religiosity-is associated with later age of sexual debut (Hull et al., 2011). For religiosity, we used a 4-point scale that measured the frequency of religious service attendance: $0=$ never, $1=$ less than once $a$ month, 2 = once $a$ month or more, 3 = once a week or more. We used parental education as a proxy variable representing socioeconomic status with a dichotomous variable indicating whether at least one parent had earned at least a college degree (yes $=1$; no $=0$ ).

\section{Developmental Characteristics}

Early pubertal development is associated with sexual debut; early-maturing adolescents, on average, enter romantic and sexual relationships earlier than their on-time or late-maturing peers (Baams et al., 2015). We used perceived pubertal timing, or the degree to which one thinks his or her physical development is advanced in comparison to their same'age, same-sex peers. Perceived pubertal timing was dichotomized as on time or early (i.e., looking older or looking one's age; 1) versus late (i.e., looking younger; 0).

\section{Behavioral Characteristics}

Adolescents and their friends tend to behave similarly across contexts (Dishion, 2013; Dishion, Ha, \& Véronneau, 2012). For example, adolescents' underage drinking is, in part, a function of their susceptibility to peer influences and a source of friendship homophily (Cheadle et al., 2013). Drinking reduces inhibition and impulse control, and as a result, increases the likelihood of sexual behaviors, including sexual debut (Kreager \& Haynie, 2011). Therefore, we controlled for binge drinking. Binge drinking in the past 12 months was coded as $0=$ never, 1 = once a month or less, and $2=$ over once a month. Academic performance is frequently similar among friends, and strong academic achievement is associated with later sexual debut (Shin \& Ryan, 2014; Halpern, Joyner, Udry, \& Suchindran, 2000). We calculated respondents' grade point average (GPA) at each time point from their reported grades in English and languages arts, mathematics, history and social studies, and science. Similarly, friendships may form from propinquity; being in close proximity to others increases the odds of interacting with and befriending others (Schaefer, Simpkins, Vest, \& Price, 2011). To account for friendships due to propinquity, we controlled for extracurricular activities. Adolescents reported their participation in up to 30 activities (e.g., sports, academic clubs, honor societies). We followed Haas and Schaefer's (2014) approach by constructing a "dyadic"-level variable, where the number of shared activities was counted for each dyad.

\section{Analysis Plan}

Our analytic goal was to simultaneously model both selection and influence on sexual debut status and to examine how gender complicates those processes. To that end, we used SAB models, a type of model that represents network dynamics by focusing on how each actor (i.e., adolescent) changes his or her ties to peers and how these actions collectively shape the evolution of the network (Snijders et al., 2010). This approach typically uses network panel data to explicitly take into account the complex dependency in network and behavioral changes. The SAB model also captures other "endogenous" patterns-for example, reciprocity, popularity, and transitivity - that would confound homophilous associations. All analyses were conducted in the Simulation Investigation for Empirical Network Analysis (SIENA) package (version 1.1-296, released August 18, 2016) in the R statistical software., which implements simulations as a sequence of microsteps (Ripley, Snijders, Boda, Vörös, \& Preciado, 2016). Each microstep is an opportunity for an actor to change his or her ties or behaviors. The parameter estimates for selection and socialization express the correspondence between simulations and the observed pattern of change in the data.

Our behavioral outcome, sexual debut, was a nondecreasing variable over time with values of 0 and 1 . That is, adolescents cannot change their sexual debut status from 1 to 0 . This feature of the behavioral outcome variable required a different model that is similar to an event history framework for "adoption" of behaviors over a given population. Behavioral "rate" functions in SIENA made it possible to model first 
sex by specifying the relative rate at which the event occurs on an individual level (Greenan, 2015). In this framework, "adoption" times follow a proportional hazard model while still predicting network formation with a SAB model. This analytic technique has been applied to other adolescent outcomes that have onsets, such as alcohol consumption and cannabis smoking (Light, Greenan, Rusby, Nies, \& Snijders, 2013). Our primary predictor variable was the number of one's friends who have had sexual intercourse at a prior wave.

Some features of friendship selection and influence are likely generalizable across contexts, whereas other features are context specific. An example of a generalizable feature of friendship selection and influence is age homophily. Because grade levels and curricula are age graded-for example, ninth graders are typically 14-15 years old and are required to take specific courses-adolescents spend a significant amount of time with their same-age peers. As a result, adolescents are more likely to befriend sameage peers than older or younger peers, regardless of the high school they attend. Opportunities to befriend same-race peers, however, are constrained by the racial composition of the student population. In other words, same-race friendships are more common in schools that lack diversity. To consider potential variability at school settings, we tested for school-level differences by using the multigroup option in the RSiena package, which ran separate models for each school and helped determine significantly different school-level effects with $t$ tests (Ripley et al., 2016). Network cohesiveness, racial and age homophily, and GPA popularity effects significantly differed between the two schools. Once school-level effects were identified, we allowed those effects to vary by including an interaction term with the respondent's school. However, most parameters-including our main variables of sexual debut status and gender-did not differ significantly by school. This multigroup model also gave separate parameters for network and behavioral change rates per period. We applied the SIENA framework for the two-school sample by treating schools as distinct networks by simultaneously assuming no network ties exist between them and allowing variability for parameters between them.

\section{Results}

\section{Descriptive Overview of Network Characteristics}

Table 1 provides descriptive information on our sample and friendship characteristics by each school. "Jefferson High School" $(n=832)$ was in the Midwest and was predominantly White, whereas "Sunshine High School" $(n=1,734)$ was located in the West and was racially diverse. Networks in Jefferson High School are closer knit and denser than networks in Sunshine High School, as indicated by higher density, average degree, and reciprocity for the former than the latter. The number of respondents who reported having sex increased and reached more than half by Time 3 for both schools $(57.8 \%, 58.9 \%)$. Both schools had similar age distribution and gender composition. The data met the criterion for modeling social network changes, as the Jaccard index, a measure of network stability between time points, was larger than 0.2 (Snijders et al., 2010).

\section{Presence and Development of Sexual Homophily}

We now turn to the results of the SAB model. Table 2 presents parameter estimates for friendship selection (upper half) and sexual behavior (lower half). In Table 2, Model 1 is our baseline and includes the main effects of sexual intercourse, whereas Model 2 adds gender-specific terms for examining the differentiation of sexual homophily by gender (e.g., male ego: sexual debut; female ego: sexual debut). To estimate how adolescents' attributes influence the likelihood of friendship ties, the model specified three types of effects for each covariate: similarity, alter, and ego effects. For similarity effects, higher values indicate greater homophily between friends. For alter effects, positive values indicate more rapid increase of received friendship nominations. For ego effects, positive values indicate more rapid increase of friendship nominations. Table 2 was organized by subsections that display estimates corresponding to their respective type of effects. Omitting any of the aforementioned types of effects (e.g., binge drinking ego) would lead to overestimating the remaining types of effects (e.g., binge drinking alter and binge drinking similarity). Accordingly, we specified our model in ways that included all three types of effects for each variable. We conducted additional diagnostic tests and found adequate goodness of fit for both models (Lospinoso, 2012; Lospinoso \& Snijders, 2011).

To test our first hypothesis regarding the presence and development of sexual homophily, we focused on the similarity effects of sexual debut on friendship and peer exposure on sexual intercourse. The similarity parameter of sexual intercourse was positive and significant, which indicates that 
Table 1

Descriptive Statistics for Two-School Sample

\begin{tabular}{|c|c|c|c|c|c|c|}
\hline \multirow[b]{2}{*}{ Waves } & \multicolumn{3}{|c|}{ Jefferson $(n=832)$} & \multicolumn{3}{|c|}{ Sunshine $(n=1,734)$} \\
\hline & 1 & 2 & 3 & 1 & 2 & 3 \\
\hline \multicolumn{7}{|l|}{ Covariates } \\
\hline Sexual experience & $39.4 \%$ & \multirow[t]{8}{*}{$47.5 \%$} & \multirow[t]{14}{*}{$57.8 \%$} & $43.3 \%$ & \multirow[t]{8}{*}{$49.1 \%$} & \multirow[t]{14}{*}{$58.9 \%$} \\
\hline Male & $52.4 \%$ & & & $51.6 \%$ & & \\
\hline Age & $16.89(1.24)$ & & & $17.27(1.03)$ & & \\
\hline White & $97.3 \%$ & & & $5.5 \%$ & & \\
\hline Black & $0.2 \%$ & & & $22.5 \%$ & & \\
\hline Hispanic & $1.1 \%$ & & & $39.5 \%$ & & \\
\hline Asian & $0.9 \%$ & & & $31.1 \%$ & & \\
\hline Other & $0.5 \%$ & & & $1.3 \%$ & & \\
\hline Grade point average & $2.60(0.77)$ & \multirow[t]{6}{*}{$2.62(0.77)$} & & $2.73(0.76)$ & \multirow[t]{6}{*}{$2.51(0.79)$} & \\
\hline Binge drinking & $0.69(0.79)$ & & & $0.48(0.75)$ & & \\
\hline Religiosity & $1.27(1.20)$ & & & $2.01(1.08)$ & & \\
\hline Parental education & $0.34(0.48)$ & & & $0.36(0.48)$ & & \\
\hline Extracurricular activities & $2.15(2.06)$ & & & $1.47(2.35)$ & & \\
\hline Pubertal development & $0.44(0.50)$ & & & $0.32(0.47)$ & & \\
\hline \multicolumn{7}{|l|}{ Network } \\
\hline Density & 0.008 & 0.005 & 0.005 & 0.002 & 0.002 & 0.001 \\
\hline Average outdegree & 4.665 & 4.039 & 3.088 & 2.496 & 2.168 & 1.364 \\
\hline Reciprocity & 0.444 & 0.388 & 0.444 & 0.392 & 0.319 & 0.353 \\
\hline Jaccard index & 0.275 & 0.259 & & 0.202 & 0.233 & \\
\hline Number of ties & 2,869 & 3,345 & 1,949 & 3,073 & 3,688 & 1,617 \\
\hline$N$ & 615 & 828 & 631 & 1,231 & 1,701 & 1,185 \\
\hline
\end{tabular}

Note. Density is the ratio of the actual number of ties over the possible number of pairs given nodes. Average outdegree refers to the average number of friends that a respondent nominates. Reciprocity was calculated as the fraction of ties reciprocated over the total number of ties. Jaccard index denotes the proportion of ties that were present in consecutive waves over all the ties in the two waves.

adolescents tended to select friends whose sexual debut statuses matched their own. That is, adolescents who have had sex are more likely to have friends who also have had sex, and adolescents who have not had sex are more likely to have friends who also have not had sex. The parameter for the total exposure to sexually debuted friends was also significant and positive, which indicates that exposure to friends who have had sex positively predicted adolescents' sexual debut. Each addition of a debuted friend increased the hazard of having sex by approximately $40 \%$, exp $(.334)=1.40$. Thus, we found evidence that supports our hypothesis that sexual homophily is present in adolescent friendship networks and that socialization and selection contribute to this homophily.

Ego and alter effects further explicate the role of sexual debut in friendship selection. The ego effect estimate for sexual intercourse is negative, which suggests that adolescents who have had sex nominate fewer friends, relative to adolescents who have not had sex. The alter effect for sexual debut indicates how having sex contributes to popularity. The positive and significant alter effect for sexual debut suggests that adolescents who have had sex received more friendship nominations than did adolescents who did not have sex. Together, the ego and alter effects suggest that adolescents who have had sex are "choosier" about who their friends are, despite being highly sought after as friends by their peers.

The remaining effects in Table 2-that is, structural effects, school interactions, and rate effectsstrengthened our findings on sexual homophily for three reasons. First, our model controls for endogenous network processes that could inflate estimates of sexual debut status on friend selection. Thus, we controlled for the fact that ties tended to be reciprocated (reciprocity); adolescents often befriended friends of friends (transitive triplets); and popular students received more future friendship nominations (indegree popularity). In addition to the aforementioned structural effects, outdegree effect controlled for the overall probability of a tie, and 
Table 2

Parameter Estimates of SIENA for Friend Selection and Sexual Debut

\begin{tabular}{lllll}
\hline & \multicolumn{2}{c}{ Model 1} & & \multicolumn{2}{c}{ Model 2} \\
\cline { 2 - 3 } \cline { 4 - 5 } & Est. $S E$ & Est. $S E$ \\
\hline
\end{tabular}

Selection parameters

Structural effects

$\begin{array}{lrrrr}\text { Outdegree } & -4.716^{* * *} & .072 & -4.716^{* * *} & .075 \\ \text { Reciprocity } & 2.144^{* * *} & .038 & 2.145^{* * *} & .039 \\ \text { Transitive triplets } & 0.482^{* * *} & .018 & 0.482^{* * *} & .019 \\ \begin{array}{l}\text { Indegree popularity } \\ \quad \text { (sqrt) }\end{array} & 0.135^{* * *} & .018 & 0.135^{* * *} & .018 \\ \begin{array}{l}\text { Outdegree activity } \\ \text { (sqrt) }\end{array} & 0.019 & .018 & 0.019 & .018 \\ & & & & \end{array}$

Similarity effects: choosing alters similar to oneself

Sexual intercourse $\quad 0.195^{* * *} \quad .021$

Male Ego: Sexual

Intercourse

Female Ego: Sexual

Intercourse

$\begin{array}{lllll}\text { Male } & 0.223^{* * *} & .020 & 0.221^{* * *} & .02 \\ \text { Race } & 0.679^{* * *} & .035 & 0.677^{* * *} & .034 \\ \text { Age } & 2.436^{* * *} & .124 & 2.438^{* * *} & .122 \\ \text { Parental education } & 0.075^{* * *} & .021 & 0.076^{* * *} & .022 \\ \text { Religiosity } & 0.110^{* * *} & .030 & 0.111^{* * *} & .034 \\ \text { Binge drinking } & 0.234^{* * *} & .036 & 0.231^{* * *} & .035 \\ \text { GPA } & 0.472^{* * *} & .056 & 0.471^{* * *} & .052 \\ \text { Shared extracurricular } & 0.194^{* * *} & .016 & 0.195^{* * *} & .017\end{array}$

activities

Alter effects: who is more often nominated?

Sexual intercourse $\quad 0.087^{* * *} \quad .022$

Male ego: Sexual

intercourse

Female ego: Sexual

intercourse

$\begin{array}{lrrrr}\text { Male } & 0.028 & .019 & 0.029 & .022 \\ \text { Age } & -0.006 & .012 & -0.006 & .012 \\ \text { Parental education } & 0.016 & .022 & 0.016 & .022 \\ \text { Religiosity } & -0.009 & .008 & -0.009 & .009 \\ \text { Binge drinking } & 0.018 & .016 & 0.016 & .016 \\ \text { GPA } & 0.022 & .016 & 0.022 & .015\end{array}$

Ego effects: who nominates more alters?

Sexual Intercourse $\quad-0.125^{* * *} \quad .024$

Male ego: Sexual

intercourse

Female ego: Sexual

$-0.024$

.026

$-0.102^{* * *}$

.028

intercourse

\begin{tabular}{|c|c|c|c|c|}
\hline Male & $0.101^{* * *}$ & .022 & $0.185^{* * *}$ & .034 \\
\hline Age & $-0.053^{* * *}$ & .012 & $-0.053^{* * *}$ & .012 \\
\hline Parental education & 0.010 & .027 & 0.008 & .023 \\
\hline Religiosity & $-0.041^{* * *}$ & .011 & $-0.041^{* * *}$ & .011 \\
\hline Binge drinking & $0.041^{*}$ & .017 & $0.039^{*}$ & .017 \\
\hline GPA & -0.001 & .015 & -0.001 & .015 \\
\hline Sunshine school & $-1.808^{* * *}$ & .118 & $-1.821^{* * *}$ & .116 \\
\hline \multicolumn{5}{|c|}{ chool interactions (Sunshine $=1$ ) } \\
\hline Transitive triplets & $0.098^{* * *}$ & .028 & $0.098^{* * *}$ & .030 \\
\hline
\end{tabular}

Table 2

Continued

\begin{tabular}{|c|c|c|c|c|}
\hline & \multicolumn{2}{|c|}{ Model 1} & \multicolumn{2}{|c|}{ Model 2} \\
\hline & Est. & $S E$ & Est. & $S E$ \\
\hline $\begin{array}{l}\text { Outdegree activity } \\
\text { (sqrt) }\end{array}$ & $0.230^{* * *}$ & .032 & $0.232^{* * *}$ & .034 \\
\hline Same race & $1.085^{* * *}$ & .076 & $1.091^{* * *}$ & .073 \\
\hline Age similarity & $0.618^{* *}$ & .218 & $0.617^{* *}$ & .207 \\
\hline Religiosity ego & $-0.095^{* * *}$ & .021 & $-0.097^{* * *}$ & .020 \\
\hline GPA alter & $0.126^{* * *}$ & .029 & $0.126^{* * *}$ & .027 \\
\hline \multicolumn{5}{|l|}{ Rate effects } \\
\hline Jefferson, Period 1 & $13.874^{* * *}$ & .527 & $13.855^{* * *}$ & .602 \\
\hline Jefferson, Period 2 & $15.330^{* * *}$ & .721 & $15.348^{* * *}$ & .802 \\
\hline Sunshine, Period 1 & $11.492^{* * *}$ & .552 & $11.490^{* * *}$ & .517 \\
\hline Sunshine, Period 2 & $9.504^{* * *}$ & .494 & $9.501^{* * *}$ & .434 \\
\hline \multicolumn{5}{|l|}{ Behavior parameters } \\
\hline $\begin{array}{l}\text { Debuted peer } \\
\text { (total exposure) }\end{array}$ & $0.334^{* * *}$ & .074 & $0.332^{* * *}$ & .079 \\
\hline $\begin{array}{l}\text { Male: Debuted peer } \\
\text { (total exposure) }\end{array}$ & & & -0.124 & .173 \\
\hline Male & -0.068 & .123 & -0.036 & .146 \\
\hline Age & $0.184^{*}$ & .082 & $0.187^{* *}$ & .067 \\
\hline Religiosity & $-0.153^{* *}$ & .057 & $-0.154^{* *}$ & .054 \\
\hline Binge drinking & $0.361^{* * *}$ & .092 & $0.363^{* * *}$ & .092 \\
\hline GPA & $-0.312^{* *}$ & .101 & $-0.313^{* * *}$ & .081 \\
\hline Pubertal development & $0.359^{*}$ & .146 & $0.362^{* *}$ & .144 \\
\hline $\begin{array}{l}\text { Extracurricular } \\
\text { activities }\end{array}$ & 0.049 & .178 & 0.050 & .149 \\
\hline $\begin{array}{l}\text { Rates for Jefferson, } \\
\text { Period } 1\end{array}$ & $0.049^{* * *}$ & .014 & $0.049^{* * *}$ & .015 \\
\hline $\begin{array}{l}\text { Rates for Jefferson, } \\
\text { Period } 2\end{array}$ & $0.348^{* * *}$ & .061 & $0.353^{* * *}$ & .082 \\
\hline $\begin{array}{l}\text { Rates for Sunshine, } \\
\text { Period } 1\end{array}$ & $0.077^{* * *}$ & .018 & $0.078^{* * *}$ & .018 \\
\hline $\begin{array}{l}\text { Rates for Sunshine, } \\
\text { Period } 2\end{array}$ & $0.449^{* * *}$ & .058 & $0.451^{* * *}$ & .074 \\
\hline $\begin{array}{l}\text { Overall maximum } \\
\text { convergence ratio }\end{array}$ & 0.230 & & 0.248 & \\
\hline
\end{tabular}

Note. Convergence $t$-ratios for all parameters are below .100 . Values are unstandardized contributions to log probabilities. Indegree popularity refers to the extent to which popular students receive more future friendship nominations. Outdegreeactivity tests whether adolescents who named more friends were more likely to add more friends at a later point. Interaction terms in this model refer to the product of the gender dummy, sexual debut covariate, and network functions and differ from the traditional regression model's approach where all relevant combinations of covariates are multiplied. SIENA $=$ Simulation Investigation for Empirical Network Analysis; GPA = grade point average.

${ }^{*} p<.05 .{ }^{* *} p<.01 .{ }^{* * *} p<.001$ (two-tailed tests).

outdegree-activity parameter tested whether adolescents who nominated more friends were more likely to add more friends at a later time. Outdegree activity was the only estimate of structural effects that 
was not significant. Rate effects by school capture the volume of friendship change between each time point. Second, we also controlled for homophily based on demographic characteristics, shared interests, and propinquity. Finally, our multigroup model addressed potential heterogeneity between the two schools (Haas \& Schaefer, 2014; Snijders \& Baerveldt, 2003). We included a Sunshine school dummy as a special case in ego effects to take into account that school sample's lower average number of friend nominations (outdegree). We created interaction terms with this school dummy variable for a few structural parameters and individual attributes that significantly differed across the schools. The results were reported in the school interactions subsection in Table 2. With these statistical controls, our estimates of sexual homophily are more reliable and more robust.

\section{Differentiation of Sexual Homophily by Gender}

Model 2 in Table 2 presents our results for our second hypothesis, which focused on the differentiation of sexual homophily by gender. We hypothesized that there would be a gender difference in adolescents' preferential bias for peers whose sexual debut statuses matched their own over peers whose sexual debut statuses did not match their own. We expected that girls would befriend same sexual debut status peers more than boys would befriend same sexual debut status peers. Testing our second hypothesis required estimating the sexual debut status effects on friendship formation for girls and boys separately. Accordingly, one estimate refers to the likelihood of a boy befriending a peer whose sexual debut status is the same as his own over a peer whose sexual debut status is different from his own, and the other estimate refers to the likelihood of a girl befriending a peer whose sexual debut status is the same as her own over a peer whose similar debut status is different from her own. By comparing the magnitudes of these two gender-specific estimates, we can discern whether sexual homophily is greater for girls than for boys. Model 2 introduces these terms by multiplying the (noncentered) dichotomous variable for girls and boys with sexual debut status covariate's ego, alter, and similarity parameters. The main effect terms for sexual debut status used in Model 1 were omitted in Model 2 to prevent perfect multicollinearity, as the new gender-specific covariate terms covered all possible ties based on gender-sexual debut status combinations: debuted girl, debuted boy, nondebuted girl, and nondebuted boy. Model 2 also adds similar specifications for the behavioral predictors of sexual debut. That is, the term male:debuted peer (total exposure) allowed us to test whether boys were more likely than girls to follow their friends' sexual debut. The results are presented in Model 2 in Table 2. For more clarity on the differential effects of sexual homophily by gender, the coefficient estimates for the key gender-specific sexual debut status terms for friendship selection are depicted with 95\% confidence intervals in Figure 1.

It appears that sexual debut shapes friendships very differently for girls and boys in school. First, girls' sexual homophily was more pronounced than boys'. For the similarity effects, the female ego:sexual intercourse similarity $($ same $=1)$ term directly compares the likelihood of a girl nominating a peer of same sexual debut status against a girl nominating a peer of different sexual debut status. The magnitude of the effects were plotted in the first panel of Figure 1. The coefficient estimate was positive and significant, indicating that girls tended to befriend peers whose sexual debut statuses matched their own than peers whose sexual debut statuses did not match their own. The estimate of the same term for boys was also positive and significant but substantially lower than girls'. In other words, boys also exhibited a preferential bias for same sexual debut status peers over different sexual debut status peers, but this bias was weaker among boys than among girls. Therefore, boys' friendship networks were more heterogeneous than girls' friendship networks in terms of friends' sexual debut statuses. We provide model-predicted propensities to select peers based on matched and unmatched sexual debut statuses in a selection table (see Appendix).

The ego and alter effects of the gender-specific sexual debut effects further reveal nuanced friendship selection processes that mirror the sexual double standard. Turning to the alter-type effects in Model 2 in Table 2 (see second panel of Figure 1), the male ego:sexual debut alter term was positive and significant, and the female ego:sexual debut alter term was positive albeit not significant. In other words, boys who have had sex became more popular (i.e., received more friendship nominations) than boys who have not had sex; for girls, however, there was no difference in popularity between girls who have and have not had sex. Similarly, this gender differentiation appeared for the ego effects (see the third panel of Figure 1). The estimate for female ego:sexual debut ego term was negative and significant, which suggests that girls who have had sex nominated fewer peers as their friends than did nondebuted girls. The estimate for male ego:sexual debut ego term was not significant, which indicates 


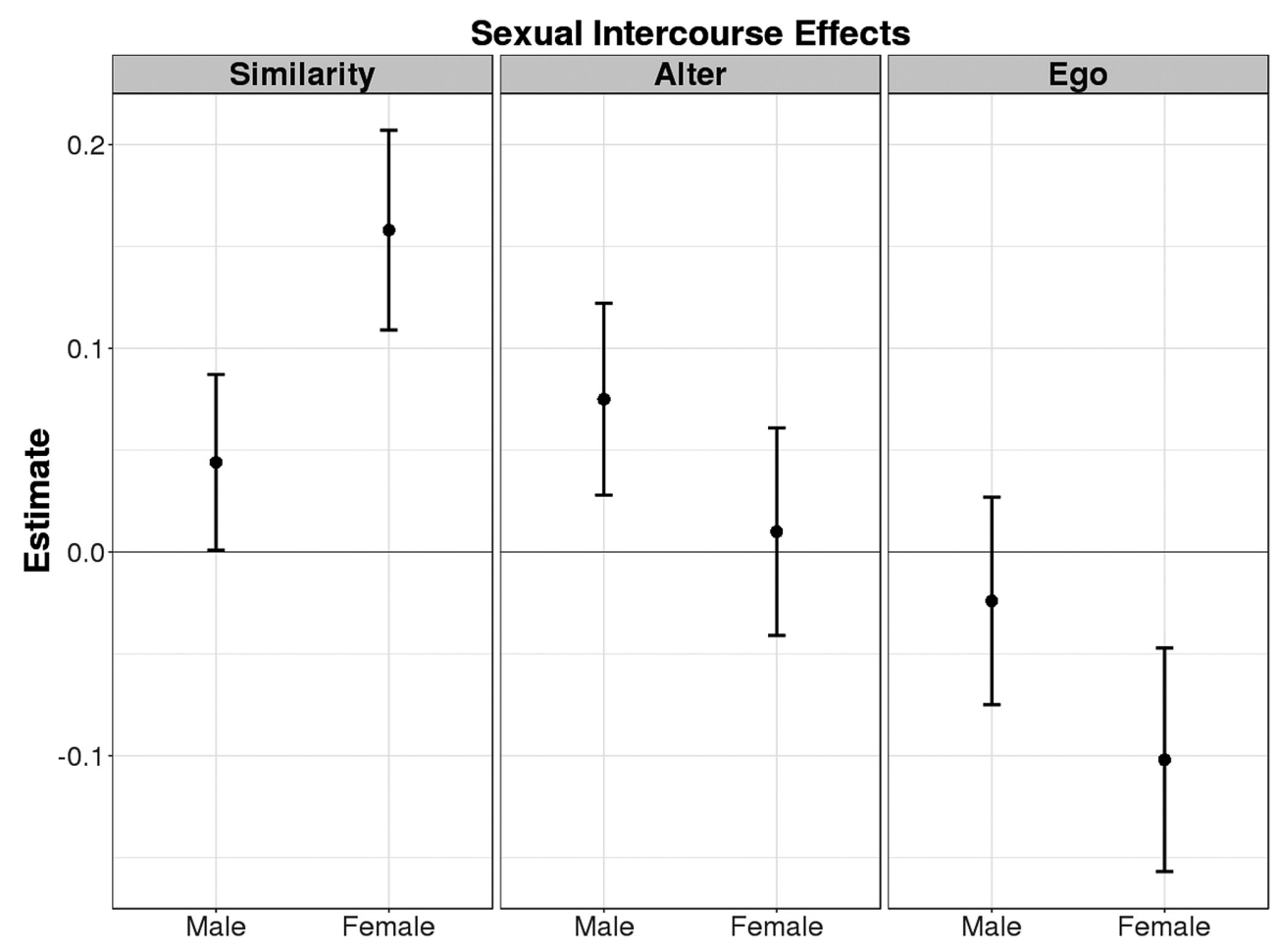

Figure 1. The differential effects of sexual debut on friendship formation by gender.

Note. This plot reports the estimates of the gender and sexual intercourse interaction terms predicting friendship formation, displaying $95 \%$ confidence intervals calculated from Model 2 in Table 2 . The panels were organized by the different types of effects: similarity (higher values indicating greater similarity in friends than not), alter (positive values indicating more rapid increase of received nominations), and ego effects (positive values indicating more rapid increase of nominations).

that boys who have had sex and boys who have not had sex nominate a similar number of friends.

Given that girls were more likely to befriend peers who matched their sexual debut status, it broaches the question of whether girls' susceptibility to their friends' sexual debut is greater than boys'. We did not find a significant difference between girls' and boys' susceptibility to their friends' sexual debut. Although the number of debuted friends (total exposure) still significantly increased the hazard of first sex in Model 2, the estimate for male:debuted peer (total exposure) was negative but not statistically significant. This suggests that there is no difference between the number of debuted friends associated with girls' and boys' transition to their sexual debut. This null finding does not necessarily conflict with our key results on the gender difference in sexual homophily via friendship selection; rather, it undergirds our predictions. That is, girls' tendency to be similar to their friends was not because they were more strongly influenced by their friends' behaviors than were boys (socialization); instead, girls exhibited greater preferential bias for peers who share their sexual debut status than boys did (selection). Consistent with our hypotheses, we found supporting evidence for (a) the presence of sexual homophily in adolescents' friendship networks; (b) the contributions of both selection and socialization to the development of sexual homophily in general; and finally (c) the differentiation of sexual homophily by gender.

\section{Discussion}

The present study investigates commonplace assumptions that provoke unease and suspicions in adults; that is, friends have an undue influence on adolescents' sexual experiences. We found evidence that supports and complicates this dominant narrative that portrays peers as problematic sexual socialization agents. Our findings suggest that friends influenced girls' and boys' sexual debut. Having friends who already had sex increased the odds of adolescents' own sexual debut. However, sexual homophily did not stem solely from socialization. We found that adolescents were more likely to befriend peers whose sexual debut statuses were the same as their own than to befriend peers with different sexual debut statuses. We also found 
considerable support for our claim that sexual homophily would be greater among girls than among boys. Girls exhibited greater sensitivity to sexual debut status in their friendship selection than did boys. Moreover, girls tended to shrink their networks after their sexual debut by increasingly turning to others whose sexual experiences matched their own. Boys, however, were less hesitant about befriending peers whose sexual debut statuses were different from their own. Boys - unlike girls - also became more popular after their sexual debut. There was, however, no difference between girls' and boys' susceptibility to their friends' influences. This suggests that the gender difference in sexual homophily was shaped more by friendship selection processes that upheld the sexual double standard. This discovery-the balance of selection by gender-is novel and hints at the nuances in social network processes. Ultimately, the present study yielded mixed support for popular beliefs that peer pressure to "just do it" leads to "everyone is doing it," and as a result, enriches our understanding of adolescent sexual homophily.

Our SAB models yielded insights that were not possible from more traditional approaches, and as a result, our study makes several unique contributions. We found that having friends who have had sex increases the likelihood of adolescents' own sexual debut, which has often been hypothesized but less rigorously tested (e.g., Brady, Dolcini, Harper, \& Pollack, 2009; Lyons et al., 2011; Sieving, Eisenberg, Pettingell, \& Skay, 2006; Wolff \& Crockett, 2011). Adolescents' odds of sexual debut were elevated when their friends had already had sex, even after controlling for shared demographic characteristics, extracurricular activities, pubertal development, risk-taking behaviors (i.e., binge drinking), and endogenous processes underlying friendships (e.g., transitive triplets, popularity, reciprocity). These statistical controls for similarities and processes were rarely possible in the past, which rendered less reliable peer effects (Jaccard et al., 2005). Moreover, friends' influence on adolescent sex is striking and distinct in the adolescent peer relations literature, which has focused extensively on public behaviors such as smoking and drinking (Brechwald \& Prinstein, 2011). Sex, on the other hand, is generally a private behavior. Homophily based on private behaviors demonstrate that peer influence processes are not dependent on social learning.

Asymmetrical patterns of friendship nominations suggest that adolescents view their own and their peers' sexual debut statuses through gendered lenses. We found evidence supporting our hypothesis that friendship selection varied by gender in ways that were generally consistent with the sexual double standard. For example, we found that boys who have had sex receive more friendship nominations than boys who have not had sex. This status boost corroborates extensive research that documents the social rewards tied to boys' masculinity. Sexual experiences affirm boys' masculinity, strengthen their friendships with other boys, confer peer approval, and increase their social standing (e.g., Cohan, 2009; Kimmel, 2009; Reigeluth \& Addis, 2016). Our study also illustrates that boys' friendship networks had lower levels of sexual homophily relative to girls'. Because boys are rewarded for accumulating sexual partners and experiences, and are sanctioned for far fewer "transgressions" than their female peers, they have more "leeway" (Kimmel, 2009; Tolman, 2002). As a result of this "leeway," boys' concerns about their own level of sexual experience and their peers' levels may be qualitatively different from girls' concerns. That is, boys may place more importance on sexual experience as a function of popularity than as a basis for friendship formation.

For girls, sexual experience is not unilaterally tied to peer acceptance; girls may be labeled a "prude" or a "slut" (Phillips, 2000; Tolman, 2002). Due to this precarious dilemma, girls who have had sex may take a more cautious approach to friendship selection. Indeed, we found that girls who have had sex nominate fewer peers as friends. Moreover, following their sexual debut, girls appear to "curate" their friendship networks by associating with similar others. Compared to boys, girls were less likely to befriend other peers whose sexual debut statuses did not match their own. This preferential bias toward similar others may serve a protective function; girls may feel more validated and safer in the company of peers who are like them. After all, girls' negative judgment is likely reserved for dissimilar others because judging others for doing what they also have done would be hypocritical. Yet, it is important to note that alternative processes may be at work. For example, network reduction may be status driven. Dijkstra et al. (2013) argued that high-status adolescents' selectiveness may reflect a need to protect their status by distancing themselves from lower status peers. Accordingly, it is also possible that girls who have had sex may see themselves as having a higher status than girls who have not had sex, and the former may try to protect their status by distancing themselves from the latter. Ultimately, these asymmetric patterns reinforce sexual homophily by reducing 
the odds of friendship formation between dissimilar others.

Our study contributes an integrated and dynamic model that predicted both friendship selection and friends' influence on sex with explicit control parameters, yet there are still some limitations. First, the stochastic actor-oriented approach makes many assumptions about the data when estimating model parameters. For example, it is assumed that the opportunities for behavioral and network changes are random and that there are no unobserved factors, other than the specified forms of the model affecting the interdependencies among the actors. Little is known about how violations of such assumptions would affect the results. Second, the fact that our longitudinal network analysis simulates concurrently interlocking causal processes should not be translated into a proof of causation. Instead, our results highlight the interdependent nature of sexual behavior and peer selection by investigating a large set of selection- and influence-related factors and thereby addressing competing explanations.

Our findings must be interpreted with caution by considering the contexts and limitations of the data. It is unclear if results would differ across schools. Schools are diverse and vary by type (e.g., public, private, charter), size, and student population (e.g., demographics). Replication across diverse school contexts is necessary to determine the generalizability of our findings. Moreover, newer data are needed to determine if our findings, which were derived from data collected in the mid-1990s, are pertinent to today's youth. Cohort differences in sexual behaviors and attitudes may emerge because sexual mores in the 1990s may be different from current mores. Analyses of birth cohorts since 1960 demonstrate that the median age of sexual debut has hovered steadily between 17 and 18 years old (Finer \& Philbin, 2014). Yet, in recent years, fewer adolescents are initiating sex early (Guttmacher Institute, 2016). Similarly, there is evidence to suggest that endorsement of sexual double standards is steady, overall, but varies a bit across situational factors (Bordini \& Sperb, 2012). Although secular and historical trends are rarely brought to the fore, doing so would enrich our understanding and examination of adolescent development.

The findings of the present study evoke several questions for future research. It is unclear whether sexual homophily persists in later life. In late adolescence and emerging adulthood, sexual debut wanes in importance because the majority of young people are sexually active. Yet, the sexual double standard persists, and late adolescent and emerging adult women still report reputational concerns (Hamilton \& Armstrong, 2009). Do young women continue to select friends whose sexual experiences are similar to their own, and if so, which index or indices of sexual experience serve as the basis for such comparisons? The stability of sexual homophily is also unclear, especially given that diverse sexual trajectories have been found in the United States (Halpern \& Haydon, 2012). This diversity stems, in part, from group (e.g., race, culture) and individual (e.g., formative sexual socialization experiences) differences. The ways in which adolescents influence and police their peers is indubitably informed by and informs their cultural values and social identities. Our understanding of adolescent friendship networks and sexual homophily will be enriched by expanding our work to include understudied populations.

Research on sexual homophily in adolescent friendship networks can serve as a promising resource for educators and health practitioners who are dedicated to promoting adolescent health. Evidence of sexual homophily suggests that adolescents are attuned to and influenced by their friends' experiences and attitudes. Because sexual beliefs may differ between friendship groups, each group may encounter different risks (Brown et al., 1997). Therefore, tailoring content to adolescents and their friends is likely more effective than delivering resources and information to adolescents en masse. For example, adolescents who endorse traditional gendered sex roles - that is, boys are sex driven and girls are passive partner pleasers - report more experiences of unwanted sex and risky sex (Sionéan et al., 2002; Teitelman, Tennille, Bobinski, Jemmott, \& Jemmott, 2011). Comprehensive sexuality education that focuses on gender, power, and rights has been shown to reduce unintended pregnancies and sexually transmitted infections (Haberland \& Rogow, 2015). Relative to adolescents who do not believe in abstinence until marriage, adolescents who intend to abstain from premarital sex are less likely to practice safe sex once they become sexually active (Bearman \& Brückner, 2001). For these adolescents, emphasis on harm reduction may be especially important. Although working with smaller groups is undoubtedly more laborious, the payoff may be worthwhile. Bay-Cheng, Livingston, and Fava (2013) argue that giving adolescents space to speak moves talk about sex from the black-and-white hypothetical scenarios and truisms to the messy, gray realities that adolescents actually encounter.

Peers are often seen as problematic sexual socialization agents (e.g., Best \& Bogle, 2014), but the 
reality is far more complex; adolescents and their friends fulfill numerous and multifaceted roles, including de facto sex educators, matchmakers, and arbiters of propriety (e.g., Suleiman \& Deardorff, 2015). By testing widespread albeit anecdotal assumptions - that is, sexual homophily-the present study provided nuanced insights into peer networks as sites for sexual socialization. Moreover, the present study was buttressed by the analysis of complete, longitudinal network data, a methodological strength that is still rare in the literature (Dishion, 2013). By continuing to address methodological challenges, empirical studies of peer relationships will begin to rival the theoretical advances in the literature. Ultimately, continual consideration of how peers, individually and collectively, wield influence and power will provide insights into the complexities that underscore peer social network processes.

\section{References}

Baams, L., Dubas, J. S., Overbeek, G., \& van Aken, M. A. G. (2015). Transitions in body and behavior: A metaanalytic study on the relationship between pubertal development and adolescent sexual behavior. Journal of Adolescent Health, 56, 586-598. https://doi.org/10.1016/ j.jadohealth.2014.11.019

Bamberg, M. (2004). Forms and functions of "slut bashing" in male identity constructions in 15-year-olds. Human Development, 47, 331-353. https://doi.org/10. 1159/000081036

Bay-Cheng, L. Y., Livingston, J. A., \& Fava, N. M. (2013). "Not always a clear path": Making space for peers, adults, and complexity in adolescent girls' sexual development. In E. L. Zurbriggen \& T. Roberts (Eds.), The sexualization of girls and girlhood: Causes, consequences, E resistance (pp. 257-277). New York, NY: Oxford University Press.

Bearinger, L. H., Sieving, R. E., Ferguson, J., \& Sharma, V. (2007). Global perspectives on the sexual and reproductive health of adolescents: Patterns, prevention, and potential. Lancet, 369, 1220-1231. https://doi.org/10. 1016/S0140-6736(07)60367-5

Bearman, P. S., \& Brückner, H. (2001). Promising the future: Virginity pledges and first intercourse. American Journal of Sociology, 106, 859-912. https://doi.org/10. $1086 / 320295$

Benenson, J. F., \& Christakos, A. (2003). The greater fragility of females' versus males' closest same-sex friendships. Child Development, 74, 1123-1129. https://doi. org/10.111/1467-8624.00596

Best, J., \& Bogle, K. A. (2014). Kids gone wild: From rainbow parties to sexting: Understanding the hype over teen sex. New York, NY: NYU Press.

Billy, J. O. G., Rogers, J. L., \& Udry, J. R. (1984). Friendship sexual behavior and friendship choice. Social Forces, 62, 653-678. https://doi.org/10.1093/sf/62.3.653
Billy, J. O. G., \& Udry, J. R. (1985). The influence of male and female best friends on adolescent sexual behavior. Adolescence, 20, 21-32.

Bordini, G. S., \& Sperb, T. M. (2012). Sexual double standard: A review of the literature between 2001 and 2010. Sexuality \& Culture, 17, 696-704. https://doi.org/ 10.1007/s12119-012-9163-0

Brady, S. S., Dolcini, M. M., Harper, G. W., \& Pollack, L. M. (2009). Supportive friendships moderate the association between stressful life events and sexual risk taking among African American adolescents. Health Psychology, 28, 238-248. https://doi.org/10.1037/a0013240

Brechwald, W. A., \& Prinstein, M. J. (2011). Beyond homophily: A decade of advances in understanding peer influence processes. Journal of Research on Adolescence, 21, 166179. https://doi.org/10.1111/j.1532-7795.2010.00721.x

Brown, B. B., Dolcini, M. M., \& Leventhal, A. (1997). Transformations in peer relationships at adolescence: Implications for health-related behavior. In J. Schulenberg, J. L. Maggs, \& K. Hurrelmann (Eds.), Health risks and developmental transition during adolescence (pp. 161189). New York, NY: Cambridge University Press.

Carpenter, L. M. (2002). Gender and the meaning and experience of virginity loss in the contemporary United States. Gender \& Society, 16, 345-365. https://doi.org/ $10.1177 / 0891243202016003005$

Cavanagh, S. E. (2004). The sexual debut of girls in early adolescence: The intersection of race, pubertal timing, and friendship group characteristics. Journal of Research on Adolescence, 14, 285-312. https://doi.org/10.1111/j. 1532-7795.2004.00076.x

Cheadle, J. E., Stevens, M., Williams, D. T., \& Goosby, B. J. (2013). The differential contributions of teen drinking homophily to new and existing friendships: An empirical assessment of assortive and proximity selection mechanisms. Social Science Research, 42, 1297-1310. https://doi.org/10.1016/j.ssresearch.2013.05.001

Cohan, M. (2009). Adolescent heterosexual males talk about the role of male peer groups in their sexual decision-making. Sexuality $\mathcal{E}$ Culture, 13, 152-177. https://doi.org/10.1007/s12119-009-9052-3

Conley, T. D., Ziegler, A., \& Moors, A. C. (2013). Backlash from the bedroom: Stigma mediates gender differences in acceptance of casual sex offers. Psychology of Women Quarterly, 37, 392-407. https://doi.org/10. $1177 / 0361694312467169$

Daniels, E. A., \& Zurbriggen, E. L. (2016). "It's not the right way to do stuff on Facebook:" An investigation of adolescent girls' and young women's attitudes toward sexualized photos on social media. Sexuality $\mathcal{E}$ Culture, 20, 936-964. https://doi.org/10.1007/s12119-016-9367-9

Davis, J. A. (1963). Structural balance, mechanical solidarity, and interpersonal relations. American Journal of Sociology, 68, 444-462. https://doi.org/10.1086/223401

Dijkstra, J. K., Cillessen, A. H. N., \& Borch, C. (2013). Popularity and adolescent friendship networks: Selection and influence dynamics. Developmental Psychology, 49, 1242-1252. https://doi.org/10.1037/a0030098 
Dishion, T. J. (2013). Stochastic agent-based modeling of influence and selection in adolescence: Current status and future directions in understanding the dynamics of peer contagion. Journal of Research on Adolescence, 23, 596-603. https://doi.org/10.1111/jora.12068

Dishion, T. J., Ha, T., \& Véronneau, M. H. (2012). An ecological analysis of the effects of deviant peer clustering on sexual promiscuity, problem behavior, and childbearing from early adolescence to adulthood: An enhancement of the life history framework. Developmental Psychology, 48, 703-717. https:/ / doi.org/10.1037/a0027304

Dolcini, M. M., Catania, J. A., Harper, W., Boyer, C. B., \& Richards, K. A. M. (2012). Sexual health information networks: What are urban African American youth learning? Research in Human Development, 9, 37-41. https: / / doi.org/10.1080/15427609.2012.654432

Eder, D., Evans, C. C., \& Parker, S. (1995). School talk: Gender and adolescent culture. New Brunswick, NJ: Rutgers University Press.

Finer, L. B., \& Philbin, J. M. (2014). Trends in ages at key reproductive transitions in the United States, 1951-2010. Women's Health Issues, 24, 271-279. https://doi.org/ 101016/j.whi.2014.02.002

Flood, M. (2009). Men, sex, and homosociality: How bonds between men shape their sexual relations with women. Men and Masculinities, 10, 339-359. https:// doi.org/10.1177/1097184X06287761

Greenan, C. C. (2015). Diffusion of innovations in dynamic networks. Journal of the Royal Statistical Society Series A (Statistics in Society), 178, 147-166. https://doi. org $/ 10.1111 /$ rssa.12054

Guttmacher Institute. (2016). American teens' sexual and reproductive health. Retrieved from https://www.gutt macher.org/fact-sheet/american-teens-sexual-and-re productive-health\#2

Haas, S. A., \& Schaefer, D. R. (2014). With a little help from my friends? Asymmetrical social influence on adolescent smoking initiation and cessation. Journal of Health and Social Behavior, 55, 126-143. https://doi.org/ $10.1177 / 0022146514532817$

Haberland, N., \& Rogow, D. (2015). Sexuality education: Emerging trends in evidence and practice. Journal of Adolescent Health, 56, S15-S21. https://doi.org/10. 1016/j.adohealth.2014.08.013

Halpern, C. T., \& Haydon, A. A. (2012). Sexual timetables for oral-genital, vaginal, and anal intercourse: Sociodemographic comparisons in a nationally representative sample of adolescents. American Journal of Public Health, 102, 1221-1228. https://doi.org/10.2105/AJPH.2011. 300394

Halpern, C. T., Joyner, K., Udry, J. R., \& Suchindran, C. (2000). Smart teens don't have sex (or kiss much either). Journal of Adolescent Health, 26, 213-225. https://doi. org/10.1016/S1054-139X(99)00061-0

Hamilton, L., \& Armstrong, E. A. (2009). Gendered sexuality in young adulthood: Double binds and flawed options. Gender E Society, 23, 589-616. https://doi.org/ $10.1177 / 0891243209345829$
Harper, G. W., Gannon, C., Watson, S. G., Catania, J. A., \& Dolcini, M. M. (2004). The role of close friends in African American adolescents' dating and sexual behavior. Journal of Sex Research, 41, 351-362. https:// doi.org/10.1080/00224490409552242

Harris, K. M., Halpern, C. T., Whitsel, E., Hussey, J., Tabor, J., Entzel, P., \& Udry, J. R. (2009). The National Longitudinal Study of Adolescent to Adult Health: Research design. Retrieved from http://www.cpc.unc.edu/projec ts/addhealth/design

Henry, D. B., Schoeny, M. E., Deptula, D. P., \& Slavick, J. T. (2007). Peer selection and socialization effects on adolescent intercourse without a condom and attitudes about the costs of sex. Child Development, 78, 825-838. https://doi.org/10.1111/j.1467-8624.2007.01035.x

Holman, A., \& Sillars, A. (2012). Talk about "hooking up": The influence of college student social networks on nonrelationship sex. Health Communication, 27, 205216. https: / / doi.org/10.1080/10410236.2011.575540

Hull, S. J., Hennessy, M., Bleakley, A., Fishbein, M., \& Jordan, A. (2011). Identifying the causal pathways from religiosity to delayed adolescent sexual behavior. Journal of Sex Research, 48, 543-553. https://doi.org/10. 1080/00224499.2010.521868

Impett, E. A., Schooler, D., \& Tolman, D. L. (2006). To be seen and not heard: Femininity ideology and adolescent girls' sexual health. Archives of Sexual Behavior, 35, 131-144. https:/ / doi.org/10.1007/s10508-005-9016-0

Jaccard, J., Blanton, H., \& Dodge, T. (2005). Peer influences on risk behavior: An analysis of the effects of a close friend. Developmental Psychology, 41, 135-147. https: / / doi.org/10.1037/0012-1649.41.1.135

Kandel, D. B. (1978). Homophily, selection, and socialization adolescent friendships. American Journal of Sociology, 84, 427-436. https://doi.org/10.1086/226792

Kapadia, F., Frye, V., Bonner, S., Emmanuel, P. J., Samples, C. L., \& Latka, M. H. (2012). Perceived peer safer sex norms and sexual risk behaviors among substanceusing Latino adolescents. AIDS Education and Prevention, 24, 27-40. https:/ / doi.org/10.1521/aeap.2012.24.1.27

Kim, J. L., Sorsoli, C. L., Collins, K., Zylbergold, B. A., Schooler, D., \& Tolman, D. L. (2007). From sex to sexuality: Exposing the heterosexual script on primetime network television. Journal of Sex Research, 44, 145-157. https: / / doi.org/10.1080/00224490701263660

Kimmel, M. (2009). Guyland: The perilous world where boys become men. New York, NY: HarperCollins.

Kreager, D. A., \& Haynie, D. (2011). Dangerous liasions? Dating and drinking diffusion in adolescent peer networks. American Sociological Review, 76, 737-763. https: / /doi.org/10.1177/0003122411416934

Kreager, D. A., \& Staff, J. (2009). The sexual double standard and adolescent peer acceptance. Social Psychology Quarterly, 72, 143-164. https://doi.org/10.1177/ 019027250907200205

Lefkowitz, E. S., Boone, T. L., \& Shearer, C. L. (2004). Communication with best friends about sex-related topics during emerging adulthood. Journal of Youth and 
Adolescence, 33, 339-351. https://doi.org/10.1023/B: JOYO.0000032642.27242.c1

Light, J. M., Greenan, C. C., Rusby, J. C., Nies, K. M., \& Snijders, T. A. B. (2013). Onset to first alcohol use in early adolescence: A network diffusion model. Journal of Research on Adolescence, 23, 487-499. https://doi.org/ 10.1111/jora.12064

Lospinoso, J. A. (2012). Statistical models for social network dynamics. Doctoral dissertation. Retrieved from EthOS (uk.bl.ethos.572624)

Lospinoso, J. A., \& Snijders, T. A. B. (2011, February). Goodness of fit for stochastic actor-oriented models. Presentation at the I Sunbelt Social Networks conference, St. Pete's Beach, FL.

Lyons, H., Giordano, P. C., Manning, W. D., \& Longmore, M. A. (2011). Identity, peer relationships, and adolescent girls' sexual behavior: An exploratory of the contemporary double standard. Journal of Sex Research, 48, 437-449. https://doi.org/10.1080/00224499.2010. 506679

McPherson, M., Smith-Lovin, L., \& Cook, J. M. (2001). Birds of a feather: Homophily in social networks. Annual Review of Sociology, 27, 415-444. https://doi. org/10.1146/annurev.soc.27.1.415

Mehta, C. M., \& Strough, J. (2009). Sex segregation in friendships and normative contexts across the life span. Developmental Review, 29, 201-220. https://doi.org/10. 1016/j.dr.2009.06.001

Osgood, D. W., Ragan, D. T., Wallace, L., Gest, S. D., Feinberg, M. E., \& Moody, J. (2013). Peers and the emergence of alcohol use: Influence and selection processes in adolescent friendship networks. Journal of Research on Adolescence, 23, 500-512. https://doi.org/ 10.1111/jora.12059

Phillips, L. M. (2000). Flirting with danger: Young women's reflections on sexuality and domination. New York, NY: New York University Press.

Prinstein, M. J., Meade, C. S., \& Cohen, G. L. (2003). Adolescent oral sex, peer popularity, and perceptions of best friends' sexual behavior. Journal of Pediatric Psychology, 28, 243-249. https://doi.org/10.1093/jpepsy/ jsg012

Reigeluth, C. S., \& Addis, M. E. (2016). Adolescent boys' experiences with policing of masculinity: Forms, functions, and consequences. Psychology of Men and Masculinity, 17, 74-83. https://doi.org/10.1037/a0039342

Ripley, R. M., Snijders, T. A. B., Boda, Z., Vörös, A., \& Preciado, P. (2016). Manual for SIENA 4.0 (version May 28, 2016). Oxford, UK: University of Oxford, Department of Statistics; Nuffield College. http:/ /www.stats. ox.ac.uk/siena/

Rose, A. J., \& Rudolph, K. D. (2006). A review of sex differences in peer relationship processes: Potential tradeoffs for the emotional and behavioral development of girls and boys. Psychological Bulletin, 132, 98-131. https: / / doi.org/10.1037/0033-2909.132.1.98

Schaefer, D. R., Simpkins, S. D., Vest, A. E., \& Price, C. D. (2011). The contributions of extracurricular activities to adolescent friendship networks: New insights though social network analysis. Developmental Psychology, 47, 1141-1152. https://doi.org/10.1037/a0024091

Shin, H., \& Ryan, A. M. (2014). Early adolescent friendships and academic adjustment: Examining selection and influence processes with longitudinal social network analyses. Developmental Psychology, 50, 2462-2472. https://doi.org/10.1037/a0037922

Sieving, R. E., Eisenberg, M. E., Pettingell, S., \& Skay, C. (2006). Friends' influence on adolescents' first sexual intercourse. Perspectives on Sexual and Reproductive Health, 38, 13-19. https://doi.org/10.1363/3801306

Sionéan, C., DiClemente, R. J., Wingood, G. M., Crosby, R., Cobb, B. K., Harrington, K., . . . Oh, M. K. (2002). Psychosocial and behavioral correlates of refusing unwanted sex among African-American adolescent females. Journal of Adolescent Health, 30, 55-63. https: / / doi.org/10.1016/S1054-139X(01)00318-4

Smiler, A. P., \& Heasley, R. (2016). Boys' and men's intimate relationships: Friendships and romantic relationships. In Y. J. Wong \& S. R. Wester (Eds.), APA handbook of men and masculinities (pp. 569-589). Washington, DC: American Psychological Association. https: / / doi.org/10.1037/14594-026

Snijders, T. A. B., \& Baerveldt, C. (2003). A multilevel network study of the effects of delinquent behavior on friendship evolution. Journal of Mathematical Sociology, 27, 123-151. https:/ / doi.org/10.1080/00222500305892

Snijders, T. A. B., van de Bunt, G. G., \& Steglich, C. E. G. (2010). Introduction to stochastic actor-based models for network dynamics. Social Networks, 32, 44-60. https: / / doi.org/10.1016/j.socnet.2009.02.004

Steinberg, L., \& Monahan, K. C. (2007). Age differences in resistance to peer influence. Developmental Psychology, 43, 1531-1543. https:/ / doi.org/10.1037/0012-1649.43.6.1531

Suleiman, A. B., \& Deardorff, J. (2015). Multiple dimensions of peer influence in adolescent romantic and sexual relationships : A descriptive, qualitative perspective. Archives of Sexual Behavior, 44, 765-775. https: / / doi.org/10.1007/s10508-014-0394-z

Teitelman, A. M., Tennille, J., Bobinski, J. M., Jemmott, L. S., \& Jemmott, J. B. (2011). Unwanted unprotected sex: Condom coercion by male partners and self-silencing of condom negotiation among adolescent girls. Advances in Nursing Science, 34, 243-259. https://doi.org/10. 1097 / ANS.0b013e31822723a3

Tolman, D. L. (2002). Dilemmas of desire: Teenage girls talk about sexuality. Cambridge, MA: Harvard University Press.

Umberson, D., Crosnoe, R., \& Reczek, C. (2011). Social relationships and health behavior across life course. Annual Review of Sociology, 36, 139-157. https://doi. org/10.1146/annurev-soc-070308-120011

Vanden Abeele, M., Campbell, S. W., Eggermont, S., \& Roe, K. (2014). Sexting, mobile porn use, and peer group dynamics: Boys' and girls' self-perceived popularity, need for popularity, and perceived peer pressure. Media Psychology, 17, 6-33. https://doi.org/10.1080/ 15213269.2013.801725 
van de Bongardt, D., Reitz, E., Overbeek, G., Boislard, M., Burk, B., \& Deković, M. (2017). Observed normativity and deviance in friendship dyads' conversations about sex and the relations with youths' perceived sexual peer norms. Archives of Sexual Behavior, 46, 1793-1806. https:/ / doi.org/10.1007/s10508-016-0763-x

van de Bongardt, D., Reitz, E., Sandfort, T., \& Deković, M. (2015). A meta-analysis of the relations between three types of peer norms and adolescent sexual behavior. Personality and Social Psychology Review, 19, 203-234. https: / / doi.org/10.1177/1088868314544223
Wallace, S. A., Miller, K. S., \& Forehand, R. (2008). Perceived peer norms and sexual intentions among African American preadolescents. AIDS Education and Prevention, 20, 360-369. https://doi.org/10.1521/aeap.2008.20. 4.360

Wolff, J. M., \& Crockett, L. J. (2011). The role of deliberate decision making, parenting, and friends in adolescent risk behaviors. Journal of Youth and Adolescence, 40, 1607-1622. https://doi.org/10.1007/s10964-0119644-8

\section{Appendix}

Table A1

Friendship Selection Table by Gender and Sexual Debut Status

\begin{tabular}{lccccc}
\hline & \multicolumn{2}{c}{ Boys } & & Girls \\
\cline { 2 - 6 } & \multicolumn{2}{c}{ Alter } & & Alter \\
\cline { 2 - 7 } Ego & Debuted & Not debuted & Ego & Debuted & Not debuted \\
\hline Debuted & 0.399 & 0.280 & Debuted & 0.228 & 0.071 \\
Not debuted & 0.379 & 0.348 & Not debuted & 0.174 & 0.329 \\
\hline
\end{tabular}

Note. This table shows the net effects of sexual debut status of ego (nominator) and alter (nominee) on friendship network formation (Table 2) by gender and gives the model-predicted propensities of friend selection among same-gender friends. In this table, the ego in rows sends a tie to the alter in columns; hence, it allows us to go beyond the marginal effects in Table 2 and thereby examine the prevalence of concordant pairs over discordant pairs based on sexual debut. The propensities to form sexually homophilous pairs are expressed in the diagonals, and comparisons between the diagonal values and the off-diagonal values indicate the degree of assortative selection based on sexual debut. Comparison of the diagonal and off-diagonal values for girls and boys confirm that sexual homophily is more prevalent for the former than the latter. Assuming other attributes and network characteristics are identical, the log-odds ratio for the debuted boys to select other debuted boys relative to nondebuted boys $(0.399-0.280=0.119)$ was lower than the debuted girls' log-odds selection of other debuted girls over nondebuted girls $(0.228-0.071=0.157)$. Similarly, the nondebuted boys' log-odds ratio to choose other nondebuted boys over the debuted ones was $-0.031(=0.348-0.379)$, which was also lower than nondebuted girls' log-odds ratio of befriending other nondebuted girls over debuted girls $(0.329-0.174=0.155)$. Therefore, we found support for our hypothesis that girls' tendencies toward sexual homophily are stronger than boys'. 